Citation: Fabio Boncinelli, Caterina Contini, Francesca Gerini, Caterina Romano, Gabriele Scozzafava, Leonardo Casini (2020) The Role of Context Definition in Choice Experiments: a Methodological Proposal Based on Customized Scenarios. Wine Economics and Policy 9(2): 49-62. doi: 10.36253/web-7978

Copyright: (c) 2020 Fabio Boncinelli, Caterina Contini, Francesca Gerini, Caterina Romano, Gabriele Scozzafava, Leonardo Casini. This is an open access, peer-reviewed article published by Firenze University Press (http:// www.fupress.com/wep) and distributed under the terms of the Creative Commons Attribution License, which permits unrestricted use, distribution, and reproduction in any medium, provided the original author and source are credited.

Data Availability Statement: All relevant data are within the paper and its Supporting Information files.

Competing Interests: The Author(s) declare(s) no conflict of interest.

\section{The Role of Context Definition in Choice Experiments: a Methodological Proposal Based on Customized Scenarios}

\author{
Fabio Boncinelli* ${ }^{*}$, Caterina Contini, Francesca Gerini, Caterina \\ Romano, Gabriele Scozzafava, Leonardo Casini \\ University of Florence, Department of Agriculture, Food, Environment and Forestry - \\ DAGRI, P.le delle Cascine 18, 50144 Florence, Italy \\ ${ }^{\star}$ Corresponding author. E-mail: fabio.boncinelli@unifi.it
}

\begin{abstract}
One of the most critical points for the validity of Discrete Choice Experiments lies in their capability to render the experiment as close to actual market conditions as possible. In particular, when dealing with products characterized by a large number of attributes, the construction of the experiment poses the issue of how to express the choice question providing sufficient information. Our study verifies the role of scenario definition in choice experiments and proposes a methodology to build customized scenarios by eliciting responses from interviewees on the main choice criteria, which makes it possible to render the conditions of the experiment more realistic. This methodology is applied to the case study of wine and is introduced by a systematic review of the Discrete Choice Experiments conducted on wine. The findings show that customized scenarios result in different preference estimates compared to the conventional approach. In particular, we found a significant decline in the importance of the price attribute, which could be attributed to a better definition of the product being evaluated. Moreover, the methodology is capable of gathering information on the decision-making process that would otherwise remain unobserved and that can be used for a better segmentation analysis.
\end{abstract}

JEL: D12, Q13.

Keywords: choice-based conjoint, choice modeling, experimental design.

\section{INTRODUCTION}

The market potentials of new product attributes were assessed by means of various methodological approaches including discrete choice experiments (DCEs), which are the most widely used stated preference method in the literature of applied economics and marketing (Hensher, 2010; Lancsar and Louviere, 2008; Louviere et al., 2000). This methodology consists of an attribute-based measure of benefit and is built on the hypothesis that any product can be described by its attributes and be assessed via the levels of the attributes themselves (Ryan, 2004). 
The DCEs are conducted by means of interviews that seek to reproduce a choice situation as close as possible to that of a real purchasing decision (Ben-Akiva et al., 2019). The interviewee is presented with several product alternatives that differ by the different levels of the attributes considered. The choice of these attributes and levels is a crucial point in carrying out the DCE. This issue becomes particularly important when dealing with complex products (such as wine, beer, motor vehicles, and property), the valuation of which is subject to a large number of stimuli. In fact, while considering many elements of value to describe the products can, on one hand, render the experiment more realistic, on the other hand, a large number of attributes and levels makes the experimental design difficult to manage (Hoyos, 2010), increases the variance of the error term, and entails a cognitive effort for the respondent that can become an error of evaluation (Arentze et al., 2003; Caussade et al., 2005). Moreover, it is also fundamental to not omit the attributes that are important for the majority of consumers, so as to avoid overestimating the importance of the attributes included in the choice task (Boncinelli et al., 2017; Casini et al., 2009; Corduas et al., 2013), and to avoid respondents making inferences about omitted attributes without the researcher being able to have information about them (Lancsar and Louviere, 2008). In this regard, Ben-Akiva et al. (2019) point out that the presentation of incomplete product profiles in the DCEs is a widespread issue among scholars. The same authors claim that the resulting fill-in problem puts the interviewees in the condition of making unrealistic and heterogeneous assumptions about missing attributes.

Many studies have tackled this issue defining in greater detail the context of reference where the actual choice is made. In this manner, the attributes considered important, but that are not included in the experiment, are described in context by the researcher, and therefore represent a scenario shared by all choices and all respondents. This solution presents some difficulties, however. In fact, when dealing with complex products, an excessively detailed description of the scenario can lead to high rates of no-choice, as excessively specific products are proposed that may not prove interesting to many consumers. Furthermore, scenarios with too many details would lead to creating an experiment that would be valid only for specific cases, and therefore, incapable of assuming a general value.

In order to make the experiment as realistic as possible, Ben-Akiva et al. (2019) recommend building it so as to maintain the same complexity of the real market in defining the products, possibly also incorporating the filtering heuristics in the choice of the product.
Indeed, as pointed out by Swait and Adamowicz (2001), in a real market where goods comprise many attributes, consumers often adopt filtering heuristics that consists of screening out products that fail to pass thresholds on selected attributes.

In view of making a contribution to these issues, our study proposes a methodology to build the choice experiment in which defining the scenario is based on what each interviewee states about the attributes and levels considered for the choice of the product being analyzed, according to a procedure analogous to that of filtering heuristics. It is thereby possible to obtain a choice scenario tailored to respondents' behavior. In literature, the studies that have attempted to adapt the experiment to the respondents have modified the attributes of the choice sets, applying the Adaptive Choice Experiments or Menu Choice methodologies (Contini et al., 2019; Liechty et al., 2001; Toubia et al., 2004; Yu et al., 2011). In the ambit of environmental economics, the personalization of the experiment concerned the statusquo option (see, as example, Ahtiainen et al., 2015). To our knowledge, however, there are no studies that have worked on personalizing the choice scenario, which makes our proposal the first contribution in this sense.

The article illustrates this proposal of methodology applied to the case study of wine. The choice of wine derives from the consideration that it is a complex product whose preferences depend on an abundance of extrinsic and intrinsic attributes (Charters and Pettigrew, 2007; Contini et al., 2015; Oczkowski and Doucouliagos 2015; Schmit et al., 2013). The literature review presented in the following section illustrates the way these attributes were used in building the choice experiments on wine.

In our DCE, besides the attributes used in the choice sets, the scenario was described leaving the interviewees free to choose the attributes they felt were most important from among the principal attributes of literature. Using a mixed logit model, the results of this approach are compared with those obtained by applying the conventional methodology in which the researcher chooses a priori the elements to define the scenario. Moreover, the information collected on the choice criteria of the interviewees can be utilized for further analyses on consumer behavior. In our case, for example, this information was used to obtain a more meaningful segmentation by a latent class analysis. In the discussions section, a critical analysis is performed on the methodology and several suggestions are made for a further development of studies. 


\section{LITERATURE REVIEW}

We conducted a systematic review of the articles published on the study of wine preferences from 1998 to 2019 by applying DCEs. Relevant articles were identified and gathered from two scientific article databases (Scopus, Web of Science) and a web search engine (Google Scholar) by means of using the following keywords: "choice experiment" AND "wine", "choice modeling" AND "wine", "discrete choice" AND "wine". We selected only articles published in journals indexed in WOS and Scopus, excluding conference proceedings.

We found a total of 35 studies. The various attributes that appeared in the selected articles were reclassified in the following 15 categories: "alcohol content"; "awards" includes awards and mentions in guidebooks; "brand" includes the indication of the producer, bottler, and brand notoriety; "format" includes characteristics like bottle capacity and shape; "functional properties" concerns the presence of information on health benefits; "price"; "production methods" conveys information on the production process, including various certifications of an environmental nature, such as organic; "promotion" states whether a discount is offered; "protected geographical indication" includes the geographic indications of different countries and regions like, for example, the DOCGs in Italy or the AOCs in France; "region of production"; "sulfites" i.e. the absence of added sulfites; "taste", such as, for example, fruity, sweet, tannic, and full-flavored; "typology" includes the typologies red/ white, still/sparkling, the grape variety, and the name that identifies the wines, such as, for example, Chianti or Champagne; "winery distinctiveness" includes information about the producer, such as company history, label graphics, and company web site; "consumption advice" includes advice to enhance the consumption experience by means of pairings with particular dishes, and indications on the best modalities for enjoying the wine, such as, for example, the serving temperature.

In addition to these elements, we also examined the "occasion", which is to say the special or usual situation of consumption, at home or with friends, insomuch as the preference for the attributes evaluated in the DCEs also depends on the situational variables connected with the social and physical environment in which the wine is consumed (Boncinelli et al., 2019).

The experiments reviewed utilized the aforesaid categories either to describe the choice context, which is to say the scenario defined by the researcher and shared by all of the choice sets, or as attributes that characterize the alternatives in the choice set. The different use in the choice experiment is synthetically illustrated in Table 1 , where " $\mathrm{C}$ " means that the element is used in describing the context, and " $\mathrm{A}$ " indicates that the attribute describes the choice option.

In addition to price, the review shows that the category most utilized in the literature is wine "typology", which is found in experiments both as a choice attribute (17 articles) and as a context ( 13 articles). To be more exact, the information on color and style (still or sparkling) is used in defining the context, while the information on grape variety or wine name are among the choice set attributes.

Next in line for frequency of use is the "region of production" (21 articles), which was always used in the DCEs as a choice attribute. Conversely, the "format" was almost always considered as a context variable (18 times out of 19). "Brand", "designation of origin", "production methods", "alcohol content", "taste", "winery distinctiveness", "acknowledgements", and "consumption advice" are less studied in the literature and are mostly treated as choice attributes. In particular, to date, no studies have used awards and the evaluation in specialized guidebooks as a context, which is to say that none have formulated a DCE in which the preference for awardwinning wines is evaluated. Finally, only a limited number of studies have used choice attributes like absence of added sulfites (2 articles), nutraceutical characteristics (2 articles), and offer of discounts ( 2 articles). Defining the "occasion" is used as a context variable and is found in 22 articles out of 35 . This description shows that almost all of the 15 categories of attributes considered are found in a consistent number of studies, thus confirming that the choice process of wine takes numerous attributes into account. The difficulty of implementing DCEs with all of the important attributes, however, has led researchers to select only a few attributes in making the experiments, inevitably reducing the realistic nature of the choice. In particular, in building the choice sets, an average of 4 categories are employed (each of which almost always represented by a single attribute), while the definition of the scenario involves, on the average, 1-2 categories more.

Our study proposes to surpass these limits by defining a methodology to create the DCE that makes it possible to take account of most of the attributes of the complex product that are considered important, guaranteeing sufficient effectiveness in developing the experiment.

\section{METHODOLOGY}

This section opens with a presentation of the procedure applied in our experiment; it then presents the 


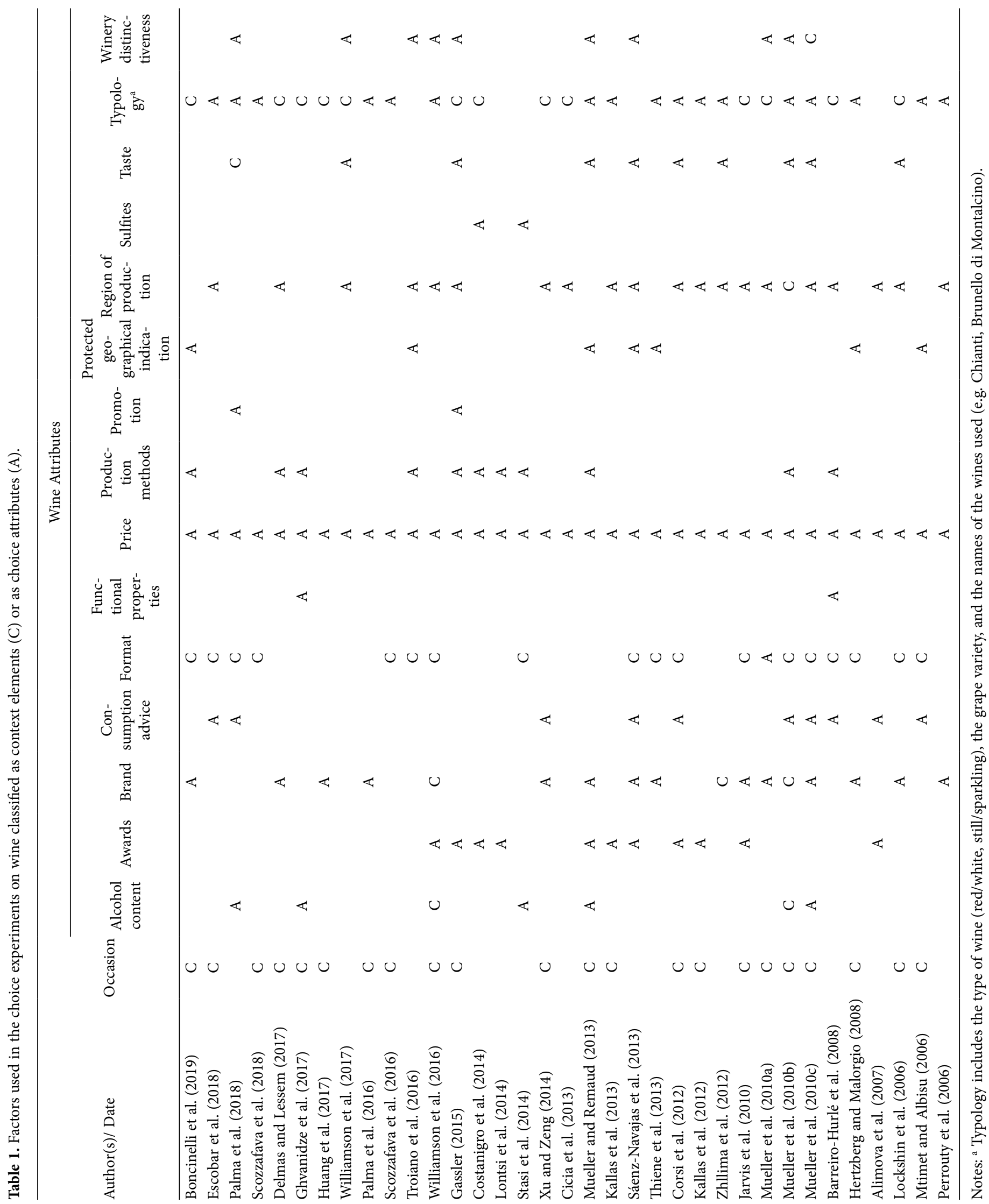


econometric model employed, and ends with a description of the sample.

\subsection{Experimental procedure}

Our experiment was conducted in January 2018 by administering an on-line questionnaire to a sample of 600 Italian wine consumers. A company specialized in market research (Toluna Inc.) handled recruiting participants and collecting data. In particular, the experiment consisted of a DCE divided into two treatments. Following a betweensubject approach, each respondent was randomly assigned to only one of the treatments. In this manner, two subsamples of 300 respondents each were formed.

We called the first treatment "limited information". It is tantamount to a conventional unlabeled DCE in which the description of the scenario conveys the information that the experiment concerned a 0.75 -liter bottle of red wine for an occasion of everyday home consumption. In the second treatment, which we called "full information", every single respondent received the same information as the first treatment, plus a description of the scenario that was more detailed and consistent with his purchasing habits. The description of the scenario was based on questions asked prior to the choice experiment.

The procedure of the second treatment can be divided into 3 steps. In the first step, respondents were asked to select, from a list we drew up based on the literature review, the criteria that they normally use in choosing wine. The criteria they could select from were: the wine's region of origin, the grape variety, the brand, alcohol content, and mention in guidebooks. In the second step, for each criterion selected, the participant was asked to select their preferred option from a dropdown menu containing the principal possible alternatives (Table 2). For example, if the interviewee indicated grape variety as a choice criterion, then he was asked to select the one he habitually preferred from a list of 20 grape varieties. In the third step, the respondents participated in a DCE where the choice scenario was defined on the basis of the information collected in phases 1 and 2. In other words, the respondents received a choice scenario "personalized" to their purchasing habits. In this manner, we were able to work around the problem that each respondent could make inferences about the attributes important for them but not included in the choice experiment and that the researcher could therefore not survey.

By way of example, the respondent who selected Tuscan wines produced from the Sangiovese grape variety and with an alcohol content of $13^{\circ}$ performed the choice experiment reported in Fig. 1.
Table 2. Information to form the choice scenario.

\begin{tabular}{|c|c|}
\hline Criteria & Available Options \\
\hline Origin & $\begin{array}{l}\text { Abruzzo, Basilicata, Calabria, Campania, Emilia } \\
\text { Romagna, Friuli-Venezia Giulia, Lazio, Liguria, } \\
\text { Lombardy, Marche, Piedmont, Apulia, Sardinia, } \\
\text { Sicily, Tuscany, Trentino Alto Adige, Umbria, Valle } \\
\text { d’Aosta, Veneto, International wine. }\end{array}$ \\
\hline Grape variety & $\begin{array}{c}\text { Aglianico, Barbera, Bardolino, Bonarda, Cabernet, } \\
\text { Cabernet Sauvignon, Cannonau, Corvina, Dolcetto, } \\
\text { Gutturnio, Lambrusco, Merlot, Montepulciano, } \\
\text { Morellino, Negroamaro, Nero D'Avola, Primitivo, } \\
\text { Sangiovese, Syrah, Teroldego, Other }\end{array}$ \\
\hline Brand & Well-known, Unknown \\
\hline Alcohol content & $\begin{array}{l}\text { Less than } 12 \%, 12 \%, 13 \%, 14 \%, 15 \% \text {, more than } \\
15 \%\end{array}$ \\
\hline $\begin{array}{l}\text { Mention in } \\
\text { guidebooks }\end{array}$ & Mentioned, Not mentioned \\
\hline
\end{tabular}

Figure 1. Example of a choice experiment.

Imagine you need to purchase a 0.75 -litre bottle of red wine from Tuscany, made from the Sangiovese grape variety and with an alcohol content of $13 \%$ for everyday consumption (which is to say not tied to special occasions). In each choice set, from among the alternatives proposed, choose the one you would purchase. In the event that none of the alternatives is to your liking, you can select the no-choice option
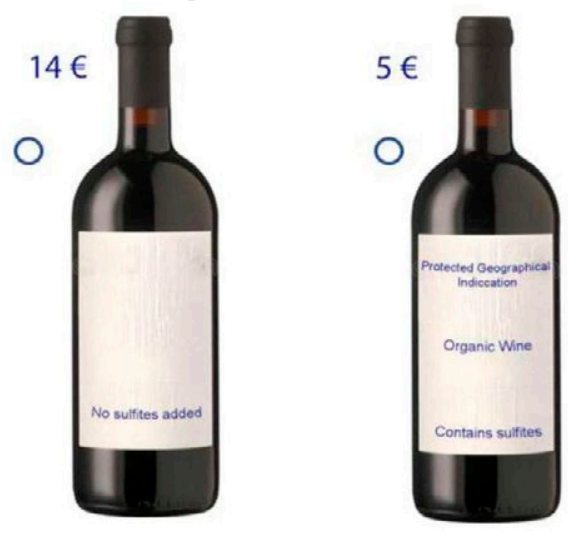

NEITHER OF THEM

The attributes included in the choice tasks, identical for the two treatments, number 4 (Table 3). The first attribute concerns the organic production method with two levels: conventional (the product does not have an organic certification) and organic (the product carries the European logo concerning organic certification). The second attribute concerns sulfites with two levels: contains sulfites, no sulfites added. The third attribute considered concerns the geographical indications (GI). The levels of GI are those regulated by the Italian classification system of GI wine (Italian Law 238/2016). The levels utilized for the GIs are: DOCG (Designation of 
Table 3. Attributes and levels in the choice experiment.

\begin{tabular}{lc}
\hline Attributes & Levels \\
\hline Organic claim & Organic, none \\
No sulfites added & No sulfites added, contains sulfites \\
Geographical indications & DOCG, DOC, IGT, none \\
Price & $€ 2, € 6, € 10, € 14$ \\
\hline
\end{tabular}

Controlled and Guaranteed Origin), DOC (Designation of Controlled Origin), and IGT (Typical Geographical Indication). The DOCG wines are subjected to stricter regulations than the DOC wines. The DOC wines instead respect stricter regulations than the IGT wines. Finally, the fourth attribute is price with 4 levels: $€ 2, €$ $6, € 10, € 14$.

Each respondent was required to answer 8 choice questions, indicating in each choice task their preferred wine between two product alternatives that differed by attribute levels. Each choice task also included a no-buy option. The experimental design was done by means of the Ngene software version 1.1.2, applying an orthogonal fractional design.

\subsection{Econometric model}

DCEs have their theoretical foundations in Lancaster's consumer theory (1966), which postulates that the utility deriving from the consumption of a certain good is a function of the same good's characteristics. We can therefore model the product's utility in function of the attributes included in the choice tasks and handle the information collected with the DCE by means of a mixed logit model (Train, 2009) that takes account of the unobserved heterogeneity across the sample.

The utility function of the individual i obtained from the choice alternative $\mathrm{j}$ in the choice task $\mathrm{t}$ is as follows:

$U_{i j t}=A S C+\alpha P R I C E_{i j t}+\boldsymbol{\beta}_{i}^{\prime} \mathbf{x}_{i j t}+\varepsilon_{i j t}$

where ASC is an alternative-specific constant that represents the no-buy option; $\alpha$ is the marginal utility of the price; PRICE represents the price levels offered to the respondent to purchase a bottle of wine; $\boldsymbol{\beta}_{i}$ is the vector of utility parameters for participant $i$; $\mathbf{x}_{i j t}$ is the vector of the wine's attributes and their levels with respect to alternative $j$, individual $i$ and choice task $t$. Finally, $\varepsilon_{i j t}$ is an unobserved random term. In the specification of our model, PRICE and ASC have been estimated as fixed coefficients, while the coefficients of the other attri- butes (organic certification, sulfites, and GI) have been assumed as independently distributed following a normal distribution. Therefore, in addition to the median effect, for each attribute, a standard deviation was estimated for each of the random components. The model has been estimated by STATA 15.1. We used the mixed logit model to compare the results of our approach with those obtained by applying the conventional methodology in which the researcher chooses a priori the elements to define the scenario.

We then created a latent class model (LCM) in order to provide an example of how the information obtained with our proposed procedure can be used to obtain a more meaningful segmentation. The LCM represents the semi-parametric version of a mixed model inasmuch as heterogeneity has a discrete distribution with $\mathrm{C}$ mass points, where $\mathrm{C}$ represents the number of classes with which the model is estimated (Greene and Hensher, 2003; Hynes and Greene, 2016). The LCM considers that every single individual belongs to a specific latent class $c$, where $c=1, \ldots, \mathrm{C}$; where all of the individuals belonging to that class have homogeneous preferences but are heterogeneous with respect to the individuals belonging to other classes. We can therefore write that following Greene and Hensher (2003), the probability that individual $i$ in the choice task $t$ chooses the alternative $j$ among the $J$ alternatives is:

$P_{i j t}=\sum_{c=1}^{c} \pi_{i c} \frac{\exp \left(\boldsymbol{\beta}_{c}^{\prime} \mathbf{x}_{i j t}\right)}{\sum_{j=1}^{J} \exp \left(\boldsymbol{\beta}_{c}^{\prime} \mathbf{x}_{i j t}\right)}$

where $\beta_{c}$ is the vector of utility parameters of class $c$. The model estimates the parameters of the attributes for each class, as well as the probability of each individual $\pi_{i c}$ to belong to a specific class $c$. This process too, can be modeled as a multinomial logit (Greene and Hensher, 2003; Ouma et al., 2007; Wu et al., 2019):

$\pi_{i c}=\frac{\exp \left(\mathbf{z}_{i}{ }^{\prime} \boldsymbol{\gamma}_{c}\right)}{\sum_{c=1}^{C} \exp \left(\mathbf{z}_{i}{ }^{\prime} \boldsymbol{\gamma}_{c}\right)}$

where $\mathbf{z}_{i}$ is the vector of the respondent's observed individual characteristics and $\gamma_{c}$ is the parameter vector for consumers in class $c$. In our case, $\mathbf{z}_{i}$ represents the criteria that respondents stated they normally use in choosing wine, which is to say the information collected in the first step of the experimental procedure with the full information group. 
Table 4. Sample composition (\%).

\begin{tabular}{lccc}
\hline & $\begin{array}{c}\text { Limited } \\
\text { information } \\
\text { scenario }\end{array}$ & $\begin{array}{c}\text { Full } \\
\text { information } \\
\text { scenario }\end{array}$ & Prob.>Chi ${ }^{2}$ \\
\hline $\begin{array}{l}\text { Gender } \\
\text { Male }\end{array}$ & 48.67 & 49.00 & \\
Female & 51.33 & 51.00 & 0.93 \\
\hline Age & & & \\
18-34 years & 24.00 & 23.00 & \\
35-54 years & 35.67 & 36.33 & \\
55-80 years & 40.33 & 40.67 & 0.95 \\
\hline Education & & & \\
Primary education & 7.67 & 7.67 & \\
Secondary education & 49.67 & 55.00 & \\
Tertiary education & 42.67 & 37.33 & 0.06 \\
\hline Geographical area & & & \\
Northern Italy & 46.67 & 47.00 & 0.99 \\
Central Italy & 18.33 & 18.00 & \\
Southern Italy and Islands & 35.00 & 35.00 & \\
\hline
\end{tabular}

\subsection{The sample}

Six hundred Italian respondents filled in the questionnaire, 300 for each treatment. All participants were screened to ensure they were over 18 years of age and had consumed wine in the previous months. The overall sample consists of approximately $48 \%$ men and 52\% women. The different age categories are well represented and most of the respondents have a secondary education. However, the consumers with a university degree are slightly over-represented. The two sub-samples have the same socio-demographic make-up as shown by the Chi-squared test (Table 4).

\section{RESULTS}

This section presents the choice criteria selected in the first step of the experiment, the results of the mixed logit models and the latent class analysis.

\subsection{Choice criteria}

Table 5 reports the frequencies with which respondents chose criteria in the course of the first step of the experiment. The information most used is origin, indicated by $77 \%$ of the respondents, followed by brand, selected by approximately $69 \%$ of the interviewees. Guidebooks are utilized by just over one-fifth of the sample and represent the criterion used less frequently.
Table 5. Frequencies with which the respondents chose criteria in the course of the first step of the experiment.

\begin{tabular}{lc}
\hline Attributes & Relative frequency (\%) \\
\hline Origin & 77.00 \\
Brand & 69.33 \\
Alcohol content & 50.00 \\
Grape variety & 49.67 \\
Mention in guidebooks & 21.67 \\
\hline
\end{tabular}

As interviewees were given the possibility to choose one or more criteria, an overall 30 combinations were chosen, the first 10 of which represent $73 \%$ of all of the respondents (Fig. 2). The combination of origin and brand is the most numerous, and is utilized by almost $14 \%$ of respondents. The successive combinations add to these two criteria, alcohol content and grape variety.

The group of respondents that utilizes all 5 criteria $(8.7 \%)$ is quite consistent, while the groups that use a single criterion are few. Among these, the most conspicuous is in fact the group that only considers origin, which represents only $4 \%$ of respondents.

The results of this first explorative analysis confirm that the choice of wine is very complex, that there are large differences between consumers, and that defining the product in creating the choice experiment can therefore be critical.

\subsection{Likelihood ratio tests for pooled models}

To test whether the coefficients between the two models are equal, we used the likelihood ratio (LR) test. The LR test is calculated as:

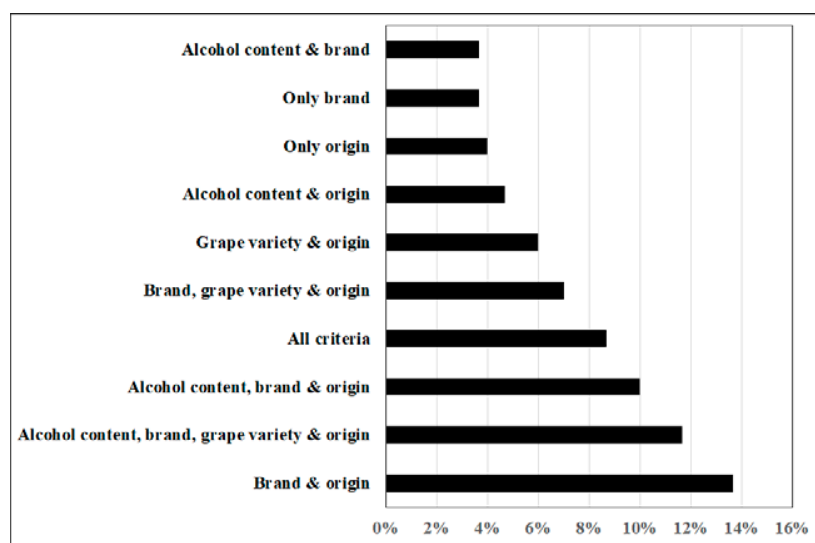

Figure 2. Frequencies concerning the first 10 combinations of the habitual choice criteria. 
Table 6. Results of the log-likelihood ratio tests.

\begin{tabular}{lcc}
\hline & Preference & \\
& Space & WTP Space \\
& Model & Model \\
\hline Log likelihood limited information scenario & -2011.78 & -1969.72 \\
Log likelihood full information scenario & -2040.38 & -1969.69 \\
Log likelihood pooled model & -4065.40 & -3951.07 \\
LR test statistics & 26.49 & 23.31 \\
Degrees of freedom & 12 & 13 \\
$p$-value & 0.009 & 0.039 \\
\hline
\end{tabular}

$L R=-2\left(L L_{\text {pooled }}-\left(L L_{\text {lim_info }}+L L_{\text {fullinfo }}\right)\right)$

where $L L_{\text {lim_info }}$ is the log-likelihood of the model applied to the sub-sample with limited information, $L L_{\text {fullinfo }}$ is that of the model for the group that received the treatment with full information, while $L L_{\text {pooled }}$ is the log-likelihood pertaining to the pooled model. The LR test has a Chi squared distribution with a number of degrees of freedom equal to the difference of the number of parameters. Table 6 reports the results of the LR test calculated both with a model specified in the utility space and with a model specified in the WTP space. The latter model serves to make sure that the results are the same in both of the specifications and to take into account the scale heterogeneity between the two subsamples. For both of the models, the LR statistics do not significantly exceed the critical values. Based on this outcome, we can affirm that the results between the two sub-samples are different.

\subsection{Parameter estimates}

Table 7 reports the results of the mixed logit models for the limited information scenario, the full information scenario, and the pooled model.

In both scenarios, the parameters of the attributes are $99 \%$ significant and bear the expected signs. With the exception of that of the IGT with limited information, the coefficients associated with the standard deviations are also all significant, which indicates a substantial heterogeneity in consumer preferences with respect to the attributes considered in the model. Specifically, the coefficient of the no-buy option is negative in both models, which indicates that the consumers receive a greater utility from choosing at least one of the options presented compared to the no-choice option. As expected, the coefficient of price is negative for both of the scenarios, indicating that the increase in price corresponds to a decrease in consumer utility. For this parameter, the magnitude is
Table 7. Results of the mixed logit models.

\begin{tabular}{|c|c|c|c|c|c|c|}
\hline \multirow[t]{2}{*}{ Attributes } & \multicolumn{3}{|c|}{$\begin{array}{l}\text { Limited Information } \\
\text { Scenario }\end{array}$} & \multicolumn{3}{|c|}{ Full Information Scenario } \\
\hline & \multicolumn{2}{|c|}{ Coef. } & 95\% C.I. & \multicolumn{2}{|c|}{ Coef. } & 95\% C.I. \\
\hline \multicolumn{7}{|c|}{ Random parameters in utility functions } \\
\hline Organic & 0.41 & $* * *$ & $(0.11 ; 0.71)$ & 0.37 & $* * *$ & $(0.09 ; 0.65)$ \\
\hline No sulfites added & 1.79 & $* * *$ & $(2.02 ; 1.55)$ & 1.73 & $* * *$ & $(1.98 ; 1.48)$ \\
\hline IGT & 0.77 & $* * *$ & $(0.47 ; 1.06)$ & 0.92 & $* * *$ & $(0.62 ; 1.22)$ \\
\hline DOC & 0.94 & $* * *$ & $(0.6 ; 1.27)$ & 0.93 & $* * *$ & $(0.61 ; 1.25)$ \\
\hline DOCG & 0.68 & $* * *$ & $(0.43 ; 0.93)$ & 0.73 & $* * *$ & $(0.49 ; 0.98)$ \\
\hline \multicolumn{7}{|c|}{$\begin{array}{l}\text { Non-random parameters in utility } \\
\text { functions }\end{array}$} \\
\hline Price & -0.10 & $* * *$ & $\begin{array}{l}(-0.13 \\
-0.08)\end{array}$ & -0.05 & $* * *$ & $(-0.08 ;-0.03)$ \\
\hline No-buy & -1.36 & $* * *$ & $\begin{array}{c}(-1.71 \\
-1.01)\end{array}$ & -0.96 & $* * *$ & $(-1.29 ;-0.62)$ \\
\hline \multicolumn{7}{|l|}{ Standard deviation } \\
\hline Organic & 0.94 & $* * *$ & $(0.74 ; 1.13)$ & 0.46 & $* * *$ & $(0.19 ; 0.74)$ \\
\hline No sulfites added & 1.20 & $* * *$ & $(0.96 ; 1.43)$ & 1.42 & $* * *$ & $(1.17 ; 1.67)$ \\
\hline IGT & -0.12 & & $(-1.04 ; 0.79)$ & 0.66 & $* * *$ & $(0.29 ; 1.03)$ \\
\hline DOC & 0.94 & $* * *$ & $(0.64 ; 1.24)$ & 0.53 & $* * *$ & $(0.15 ; 0.91)$ \\
\hline DOCG & -0.85 & $* * *$ & $(0.53 ; 1.17)$ & 0.91 & $* * *$ & $(0.61 ; 1.21)$ \\
\hline Observations & & & 7,200 & & & 7,200 \\
\hline $\mathrm{BIC}$ & & & 4130.14 & & & 4187.35 \\
\hline AIC & & & 4047.55 & & & 4104.77 \\
\hline
\end{tabular}

Notes: Asterisks indicate the following significance levels: ${ }^{*}=10 \%$; ${ }^{* *}=5 \% ;{ }^{* *}=1 \%$; Coef. $=$ Coefficient; C.I. $=$ Confidence interval.

substantially different in the two scenarios, -0.10 for the limited information scenario compared to -0.05 for the full information scenario, indicating the lesser role of the price attribute in the utility function in the latter case.

The parameters of the other attributes' levels all prove to be positive in both of the scenarios, thus indicating that the consumers prefer wines without added sulfites, with geographical indication, and organic. In particular, the absence of added sulfites is the parameter with the greatest magnitude and thus constitutes the characteristic that on a par with other conditions confers greater utility to wine.

From the analysis of the confidence intervals, we can also note that the two models substantially differ only by the parameter of price. Indeed, as we have already pointed out, the coefficient of price for the full information scenario is about half that of the limited information scenario, and the confidence intervals in the two models do not overlap.

To further verify the determinants of the differences between the two sub-samples, a new model was performed on the pooled sample, inserting variables of 
Table 8. Results of the mixed logit model with treatment interactions.

\begin{tabular}{|c|c|c|c|}
\hline Attributes & \multicolumn{2}{|c|}{ Coefficient } & $z$-value \\
\hline \multicolumn{4}{|c|}{ Random parameters in utility functions } \\
\hline Organic & 0.39 & $* * *$ & 2.65 \\
\hline No sulfites added & 1.80 & $* * *$ & 15.62 \\
\hline IGT & 0.80 & $* * *$ & 5.37 \\
\hline DOC & 0.92 & $* * *$ & 5.51 \\
\hline DOCG & 0.67 & $* * *$ & 5.25 \\
\hline \multicolumn{4}{|c|}{ Non-random parameters in utility functions } \\
\hline Price & -0.10 & $* * *$ & -9.35 \\
\hline No-buy & -1.33 & $* * *$ & -7.50 \\
\hline Treatment ${ }^{\star}$ Price & 0.04 & $* * *$ & 3.00 \\
\hline Treatment ${ }^{\star}$ No-buy & 0.33 & & 1.37 \\
\hline Treatment ${ }^{\star}$ Organic & 0.01 & & 0.06 \\
\hline Treatment ${ }^{\star}$ No sulfites added & 0.07 & & 0.48 \\
\hline Treatment ${ }^{*}$ IGT & 0.07 & & 0.36 \\
\hline Treatment ${ }^{\star}$ DOC & 0.05 & & 0.20 \\
\hline Treatment ${ }^{*}$ DOCG & 0.07 & & 0.41 \\
\hline \multicolumn{4}{|l|}{ Standard Deviation } \\
\hline Organic & 0.75 & $* * *$ & 9.47 \\
\hline No sulfites added & 1.32 & $* * *$ & 15.19 \\
\hline IGT & -0.42 & $* *$ & -2.00 \\
\hline DOC & 0.77 & $* * *$ & 6.72 \\
\hline DOCG & 0.89 & $* * *$ & 7.98 \\
\hline
\end{tabular}

Notes: Asterisks indicate the following significance levels: ${ }^{*}=10 \%$; ${ }^{* *}=5 \% ;{ }^{* *}=1 \%$.

interaction between the treatment (full information) and the attributes specified in equation 1 . The results of this different specification indicate that all of the interaction variables are not statistically significant except for the interaction variable between treatment and price (Table 8). This confirms that the full information treatment affects the parameter of price, determining a significant reduction of its importance.

Notably, the interaction between the no-buy option and treatment is also not significant, which indicates that the treatment has not affected the no-choice rate during the choice experiment. Providing the respondent with a more definite scenario by means of the proposed methodology therefore does not modify the no-choice rate.

In order to test whether the treatment also had an effect on the willingness to pay, we applied a Poe (2005) test. The results reported in table 9 show that the willingness to pay of the two sub-samples differ by the attributes No sulfites added, IGT and DOCG. The difference for the willingness to pay for the DOC attribute is significant only for $10 \%$, while the willingness to pay for the organic certification does not differ in the two treatments.
Table 9. WTP values (€ per bottle) across Treatments and Hypotheses Tests.

\begin{tabular}{lccc}
\hline & $\begin{array}{c}\text { Limited } \\
\text { Information } \\
\text { Scenario }\end{array}$ & $\begin{array}{c}\text { Full Information } \\
\text { Scenario }\end{array}$ & p-values \\
\hline $\begin{array}{l}\text { Organic } \\
\text { No sulfites }\end{array}$ & 4.09 & 7.25 & 0.199 \\
added & -17.37 & -33.18 & 0.001 \\
IGT & 7.42 & 17.78 & 0.010 \\
DOC & 9.22 & 18.22 & 0.054 \\
DOCG & 6.66 & 14.01 & 0.021 \\
\hline
\end{tabular}

We estimated p-values using the Poe (2005) test with 1,000 Krinsky and Robb (1986) bootstrapped WTP estimates.

\subsection{Latent class results}

The segmentation analysis was conducted by means of a LCM with a specification of the model with respect to the same utility function as that of equation 1 and utilizing the choice criteria of each respondent as class membership variables. We have chosen the 5 -class model based on the Bayesian Information Criterion (BIC), which shows an inversion between the models with 5 and 6 classes (Table 10).

The results of the LCM (Table 11) show a marked heterogeneity in consumer preferences indicated by the strong differences between classes as per significance, magnitude, and sign of the utility function parameters.

For example, the price coefficient is negative and significant for classes 1 and 3, positive and significant for classes 4 and 5, and not significantly different from zero for class 2. Organic certification is instead significant only for class 5 , where it represents one of the attributes with the greatest positive impact on consumer utility. The absence of added sulfites is perhaps the most homogeneous parameter among the classes; it is indeed always significant with a positive sign even when it presents a

Table 10. Fit measures for latent class models with different numbers of classes.

\begin{tabular}{lcccc}
\hline Model & LL & BIC & AIC & Npar \\
\hline 2-Class model & -1857.609 & 3829.226 & 3755.217 & 20 \\
3-Class model & -1781.949 & 3752.013 & 3629.898 & 33 \\
4-Class model & -1717.814 & 3697.849 & 3527.629 & 46 \\
5-Class model & -1668.261 & 3672.849 & 3454.522 & 59 \\
6-Class model & -1640.347 & 3691.126 & 3424.694 & 72 \\
7-Class model & -1619.769 & 3724.075 & 3409.537 & 85 \\
\hline
\end{tabular}

Notes: $\mathrm{LL}=$ Log-likelihood; BIC $=$ Bayesian Information Criterion; $\mathrm{AIC}=$ Akaike Information Criterion; Npar $=$ Number of parameters. 
Table 11. Latent class model results.

\begin{tabular}{|c|c|c|c|c|c|c|}
\hline Attributes & Class 1 & Class 2 & Class 3 & Class 4 & Clas & ss 5 \\
\hline \multicolumn{7}{|c|}{ Utility Function Coefficients } \\
\hline Price & $-0.11 * * *$ & -0.04 & $-0.45^{* * *}$ & $0.19^{\star * *}$ & 0.18 & $* * *$ \\
\hline No-buy & $-3.85 * * *$ & $-3.06^{*}$ & $-1.96 * * *$ & 0.23 & 4.04 & $* * *$ \\
\hline Organic & 1.14 & 0.96 & -0.58 & -0.25 & 2.91 & $* * *$ \\
\hline No sulfites added & $0.33^{* *}$ & $4.65^{* *}$ & $1.46^{* * *}$ & $0.50^{* * *}$ & 4.74 & $* * *$ \\
\hline IGT & 0.76 & 1.74 & $1.67 * * *$ & $0.96 * *$ & 2.28 & $* * *$ \\
\hline DOC & 1.88 & 2.24 & $1.44^{* * *}$ & $0.79 *$ & 3.03 & $* * *$ \\
\hline DOCG & $1.15^{\star * *}$ & 4.45 & $1.19^{* *}$ & 0.38 & 0.98 & $* *$ \\
\hline \multicolumn{7}{|c|}{ Class Membership Coefficients } \\
\hline Constant & & $-1.34 * *$ & 0.44 & $-1.71 * *$ & -0.29 & \\
\hline Origin & & $1.34^{* *}$ & 0.32 & $1.22^{* *}$ & 0.15 & \\
\hline Grape Variety & & 0.07 & -0.30 & -0.56 & -0.06 & \\
\hline Brand & & 0.34 & -0.24 & 0.31 & 0.02 & \\
\hline Alcohol content & & -0.40 & -0.66 & 0.31 & -0.66 & \\
\hline Mention in Guidebooks & & 0.56 & $-1.43^{\star *}$ & 0.92 & -0.76 & \\
\hline Class Size & $25 \%$ & $23 \%$ & $22 \%$ & $17 \%$ & $13 \%$ & \\
\hline
\end{tabular}

Notes: Asterisks indicate the following significance levels: ${ }^{*}=10 \% ;{ }^{* *}=5 \% ;{ }^{* *}=1 \%$.

conspicuous variability of magnitude, passing from 0.33 for class 1 to 4.74 for class 5. The GI parameters always have a positive sign, but are not always significant. For example, they are all significant for classes 3 and 5, while for class 2, no indication of origin is significant. Class 1, which has the most consistent class size, has a significant preference only for DOCG wines, the top-tier certification.

The coefficients of class membership indicate the role of the different criteria in determining the probability of belonging to each class with respect to class 1 . The Wald test of joint difference of parameters between classes indicates that the main predictors among the classes are origin (Wald $=9.77 ; \mathrm{p}$-value $=0.044$ ) and mention in guidebooks (Wald $=16.75$; $\mathrm{p}$-value $=0.0022$ ). In particular, the probability of belonging to class 2 and 4 (40\% of respondents) depends significantly on the choice of origin. While respondents belonging to class 3 are consumers who, more than those of other classes, are more likely to disregard the judgement of guidebooks as a choice criteria of wine. The coefficients concerning alcohol content, grape variety, and brand are instead not statistically significant.

\section{CONCLUSIONS}

DCEs are a widely utilized methodology to evaluate the market potentials of new attributes of products. One of the main challenges in applying them is represented by the capability to reproduce the decision-making context in the most realistic manner possible (Ben-Akiva et al., 2019). This issue is particularly important when dealing with complex products. Their evaluation necessitates considering a great number of stimuli, and also involves a filtering heuristic, progressively screening out products that fail to pass thresholds on a selected attribute.

In the literature, creating DCEs for complex products has frequently implied the use of a large number of attributes and levels in the experimental design without, however, always succeeding in adequately reproducing the actual choice situation. Moreover, the use of a large number of attributes and levels entails important criticalities in terms of experimental design complexity and the difficulty of interviewees to reply. An enhancement of the realistic nature of the experiment can also be obtained by means of a better definition of the context in which the choice is made, but in this case, excessive detail can determine the undesired effect of a high no-reply rate, considering the fact that the product described in this manner might not prove interesting to a sufficient number of consumers.

The solution proposed here confronts this problem by means of a methodology of building the choice experiment that takes into account the actual behavior of the consumer in choosing wine. For this product, as for others with similar characteristics of complexity, the final choice derives from a filtering heuristic of the many alternative products available on the market (Swait and Adamowitcz, 2001). For example, first we choose the 
color, then the grape variety, then we consider the price, and so on until we complete the range of attributes that each consumer considers important. In attempting to make the choice experiment as realistic as possible, we therefore developed a procedure to define the scenario of reference which includes all the attributes that each interviewee considers important in their decision-making process. In greater detail, in the first phase, the respondents were asked what attributes were important for them in choosing wine. Then for each attribute selected, the main alternatives were proposed, and they were asked to select the one they preferred. The mix of options indicated in this manner was then used to define the choice scenario of each interviewee. It was thereby possible to obtain a more realistic choice situation, maintain the design within acceptable limits of complexity, and also observe the specific characteristics of the product that each interviewee referred to in his choice. The capability to identify the specific preferences that the decision-making process of wine develops along constitutes an important improvement compared to traditional procedures. Furthermore, we found significant differences in the choice criteria for wine, as far as the nature and number of attributes to consider are concerned.

Applying the procedure of tailoring the scenario of reference to the individual respondent has shown that defining the choice scenario is not neutral with respect to the choices elicited in the experiment. In fact, our approach has shown preference estimates that are significantly different from those of the conventional approach, as pointed out by the LR test. These differences proved substantial for the parameter of price, indicating that a better description of wine in the scenario of reference gave rise to a reduction in the importance of the price attribute, which can plausibly be explained by the fact that the consumer is less uncertain about the definition of the two alternatives of wine to evaluate. Our outcomes are coherent with general economic theory and with earlier consumer studies which indicate that price sensitivity is a function of available information. In this regard, Alba et al. (1997) find that having more information on quality attributes reduces price sensitivity, while Nagle and Müller (2017) suggest that consumers show lower price sensitivity when they perceive specific quality features of the product. These results call for further research on the role that the specification of the choice scenario has on preference estimates. In fact, in various case studies, an issue might arise on how detailed the product definition should be, and the adopted solution might not be neutral with respect to the results, especially in terms of WTP.

Furthermore, our results point out that the use of the "region of origin" and "mention in guidebooks" criteria, in particular, contribute to defining specific segments of consumers.

It is worth mentioning that the information acquired through the methodology proposed is greater than the information used in this paper. The numerousness of the choice options utilized by respondents, however, was such that given the size of the sample, it did not permit more in-depth segmentation analyses.

The type of approach utilized does not allow us to identify econometric indicators that define whether the procedure we propose has greater statistical properties than the traditional procedure. From the practical point of view, however, the possibility to avail ourselves of individual information on the choice criteria and on the preferred options for each choice criterion represents an important element for a better understanding of the decision-making process, and can also be used for further segmentation analyses, as proposed in the article.

In conclusion, this article represents a first contribution to achieving a more realistic decision- making context by improving the choice scenario definition in DCEs. Overall, the proposed solution offers various advantages over the traditional approaches, even though its application in different contexts and on different products could certainly make for further improvements in the phase of eliciting preferences.

\section{REFERENCES}

Ahtiainen, H., Pouta, E., Artell, J., 2015. Modelling asymmetric preferences for water quality in choice experiments with individual-specific status quo alternatives. Water Resour Econ, 12, 1-12

Alba, J., Lynch, J., Weitz, B., Janiszewski, C., Lutz, R., Sawyer, A. Wood, S., 1997. Interactive home shopping: consumer, retailer, and manufacturer incentives to participate in electronic marketplaces. J. Marketing 61 (3), 38-53.

Alimova, N., Lillywhite, J.M., Hurd, B.H., Hadjigeorgalis, E., 2007. High desert wine: a discrete choice analysis of consumer preferences for New Mexican wine. J. Food Prod. Mark. 14 (1), 1-10.

Arentze, T., Borgers, A., Timmermans, H., DelMistro, R., 2003. Transport stated choice responses: effects of task complexity, presentation format and literacy. Transport. Res. E-Log. 39 (3), 229-244.

Barreiro-Hurlé, J., Colombo, S., Cantos-Villar, E., 2008. Is there a market for functional wines? Consumer preferences and willingness to pay for resveratrol-enriched red wine. Food Qual. Prefer. 19 (4), 360-371. 
Ben-Akiva, M., McFadden, D., Train, K., 2019. Foundations of stated preference elicitation: consumer behavior and choice-based conjoint analysis. Found. Trends Econometrics 10 (1-2), 1-144.

Boncinelli, F., Contini, C., Romano, C., Scozzafava, G., Casini, L., 2017. Territory, environment, and healthiness in traditional food choices: insights into consumer heterogeneity. Int. Food Agribus. Man. 20 (1), 143-157.

Boncinelli, F., Dominici, A., Gerini, F. Marone, E., 2019. Consumers wine preferences according to purchase occasion: personal consumption and gift-giving. Food Qual. Prefer. 71, 270-278.

Casini, L., Corsi, A.M., Goodman, S., 2009. Consumer preferences of wine in Italy applying best-worst scaling. Int. J. Wine Bus. Res. 21 (1), 64-78.

Caussade, S., de Dios Ortúzar, J., Rizzi, L.I., Hensher, D.A., 2005. Assessing the influence of design dimensions on stated choice experiment estimates. Transport. Res. B- Meth. 39 (7), 621-640.

Charters, S., Pettigrew, S., 2007. The dimensions of wine quality. Food Qual. Prefer. 18 (7), 997-1007.

Cicia, G., Cembalo, L., Del Giudice, T., Scarpa, R., 2013. Country-of-origin effects on Russian wine consumers. J. Food Prod. Mark. 19 (4), 247-260.

Contini, C., Boncinelli, F., Romano, C., Scozzafava, G., Casini, L., 2019. Price vector issue in a choice experiment: a methodological proposal. Food Qual. Prefer 75, 23-27.

Contini, C., Romano, C., Scozzafava, G., Boncinelli, F., Casini, L., 2015. Wine consumption and sales strategies: the evolution of Mass Retail Trading in Italy. Wine Econ. Policy 4 (2), 116-127.

Corduas, M., Cinquanta, L. Ievoli, C., 2013. The importance of wine attributes for purchase decisions: a study of Italian consumers' perception. Food Qual. Prefer. 28 (2), 407-418.

Corsi, A.M., Mueller, S. Lockshin, L., 2012. Let's see what they have... What consumers look for in a restaurant wine list. Cornell Hosp. Q. 53 (2), 110-121.

Costanigro, M., Appleby, C. Menke, S.D., 2014. The wine headache: consumer perceptions of sulfites and willingness to pay for non-sulfited wines. Food Qual. Prefer. 31, 81-89.

Delmas, M.A., Lessem, N., 2017. Eco-premium or ecopenalty? Eco-labels and quality in the organic wine market. Bus. Soc. 56 (2), 318-356.

Escobar, C., Kallas, Z., Gil, J.M., 2018. Consumers' wine preferences in a changing scenario. Brit. Food J. 120 (1), 18-32.

Gassler, B., 2015. How green is your 'Grüner'? Millennial wine consumers' preferences and willingness-to-pay for eco-labeled wine. J. Austrian Soc. Agr. Econ. 24, $131-140$.

Ghvanidze, S., Velikova, N., Dodd, T. Oldewage-Theron, W., 2017. A discrete choice experiment of the impact of consumers' environmental values, ethical concerns, and health consciousness on food choices: a cross-cultural analysis. Brit. Food J. 119 (4), 863-881.

Greene, W.H., Hensher, D.A., 2003. A latent class model for discrete choice analysis: contrasts with mixed logit. Transport. Res. B- Meth. 37 (8), 681-698.

Hensher, D.A. 2010. Hypothetical bias, choice experiments and willingness to pay. Transport. Res. BMeth. 44 (6), 735-752.

Hertzberg, A., Malorgio, G., 2008. Wine demand in Italy: an analysis of consumer preferences. New Medit. 4, 40-46.

Hoyos, D., 2010. The state of the art of environmental valuation with discrete choice experiments. Ecol. Econ. 69 (8), 1595-1603.

Huang, A., Dawes, J., Lockshin, L., Greenacre, L., 2017. Consumer response to price changes in higher-priced brands. J. Retailing Consum. Serv. 39, 1-10.

Hynes, S., Greene, W., 2016. Preference heterogeneity in contingent behaviour travel cost models with on-site samples: A Random Parameter vs. a Latent Class Approach. J. Agr. Econ. 67, 348-367.

Jarvis, W., Mueller, S., Chiong, K., 2010. A latent analysis of images and words in wine choice. Australas. Mark. J. 18 (3), 138-144.

Kallas, Z., Escobar, C., Gil, J.M., 2012. Assessing the impact of a Christmas advertisement campaign on Catalan wine preference using choice experiments. Appetite 58 (1), 285-298.

Kallas, Z., Escobar, C., Gil, J.M., 2013. Analysis of consumers' preferences for a special-occasion red wine: a dual response choice experiment approach. Food Qual. Prefer. 30 (2), 156-168.

Krinsky, I., Robb, A. L., 1986. On approximating the statistical properties of elasticities. Rev Econ and Stat, 715-719.

Lancaster, K.J., 1996. A new approach to consumer theory. J. Polit. Econ. 74 (2), 132-157.

Lancsar, E., Louviere, J., 2008. Conducting discrete choice experiments to inform healthcare decision making. Pharmaco Economics 26 (8), 661-677.

Liechty, J., Ramaswamy, V., Cohen, S.H., 2001. Choice menus for mass customization: an experimental approach for analyzing customer demand with an application to a web-based information service. J. Marketing Res. 38 (2), 183-196.

Lockshin, L., Jarvis, W., d'Hauteville, F., Perrouty, J.P., 2006. Using simulations from discrete choice experi- 
ments to measure consumer sensitivity to brand, region, price, and awards in wine choice. Food Qual. Prefer. 17 (3-4), 166-178.

Lontsi, D.A.D., Tempesta, T., Arboretti, R., Corain, L., Salmaso, L., Tomasi, D., Boatto, V., 2014. Caractéristiques du paysage et propension à acheter du vin: une expérience de choix. New Medit 13 (3), 31-39.

Louviere, J.J., Hensher, D.A., Swait, J.D., 2000. Stated Choice Methods: Analysis and Applications. Cambridge University Press.

Mtimet, N., Albisu, L. M., 2006. Spanish wine consumer behavior: a choice experiment approach. Agribusiness 22 (3), 343-362.

Mueller, S., Remaud, H., 2013. Impact of corporate social responsibility claims on consumer food choice: a crosscultural comparison. Brit. Food J. 115 (1), 142-166.

Mueller, S., Lockshin, L., Louviere, J. J., 2010a. What you see may not be what you get: asking consumers what matters may not reflect what they choose. Marketing Lett. 21 (4), 335-350.

Mueller, S., Lockshin, L., Saltman, Y., Blanford, J., 2010b. Message on a bottle: The relative influence of wine back label information on wine choice. Food Qual. Prefer. 21 (1), 22-32.

Mueller, S., Osidacz, P., Francis, I. L., Lockshin, L., 2010c. Combining discrete choice and informed sensory testing in a two-stage process: can it predict wine market share?. Food Qual. Prefer. 21 (7), 741-754.

Nagle, T. T., Müller, G. 2017. The Strategy and Tactics of Pricing: A Guide to Growing More Profitably, New York, NY: Routledge.

Oczkowski, E., Doucouliagos, H., 2015. Wine prices and quality ratings: a meta-regression analysis. Am. J. Agr. Econ. 97 (1), 103-121.

Ouma, E., Abdulai, A., Drucker, A., 2007. Measuring heterogeneous preferences for cattle traits among cattlekeeping households in East Africa. Am. J. Agr. Econ. 89 (4), 1005-1019.

Palma, D., Ortúzar, J. D. D., Rizzi, L. I., Casaubon, G., 2018. Modelling consumers' heterogeneous preferences: a case study with Chilean wine consumers. Aust. J. Grape Wine R. 24 (1), 51-61.

Palma, D., Ortúzar, J. D. D., Rizzi, L. I., Guevara, C. A., Casaubon, G., Ma, H., 2016. Modelling choice when price is a cue for quality: a case study with Chinese consumers. J. Choice Model 19, 24-39.

Perrouty, J. P., d'Hauteville, F., Lockshin, L., 2006. The influence of wine attributes on region of origin equity: an analysis of the moderating effect of consumer's perceived expertise. Agribusiness 22 (3), 323-341.

Poe, G. L., Giraud, K. L., Loomis, J.B., 2005. Computational Methods for Measuring the Difference of
Empirical Distributions. Am. J. Agr. Econ. 87, 353365.

Ryan, M., 2004. Discrete choice experiments in health care: nice should consider using them for patient centred evaluations of technologies. Briti. Med. J. $328,360-361$.

Sáenz-Navajas, M. P., Campo, E., Sutan, A., Ballester, J., Valentin, D., 2013. Perception of wine quality according to extrinsic cues: the case of Burgundy wine consumers. Food Qual. Prefer. 27 (1), 44-53.

Schmit, T. M., Rickard, B. J., Taber, J., 2013. Consumer valuation of environmentally friendly production practices in wines, considering asymmetric information and sensory effects. J. Agr. Econ. 64, 483-504.

Scozzafava, G., Contini, C., Costanigro, M., Casini, L., 2016. Consumer response to quality differentiation strategies in wine PDOs. Agric. Agric. Sci. Procedia $8,107-114$.

Scozzafava, G., Gerini, F., Dominici, A., Contini, C., Casini, L., 2018. Reach for the stars: the impact on consumer preferences of introducing a new top-tier typology into a PDO wine. Wine Econ. Policy 7(2), $140-152$.

Stasi, A., Bimbo, F., Viscecchia, R., Seccia, A., 2014. Italian consumers' preferences regarding dealcoholized wine, information and price. Wine Econ. Policy, 3(1), $54-61$.

Swait, J., Adamowicz, W., 2001 Choice environment, market complexity, and consumer behavior: a theoretical and empirical approach for incorporating decision complexity into models of consumer choice. Organ. Behav. Hum. Dec. 86 (2), 141-167.

Thiene, M., Scarpa, R., Galletto, L., Boatto, V., 2013. Sparkling wine choice from supermarket shelves: the impact of certification of origin and production practices. Agr. Econ. 44 (4-5), 523-536.

Toubia, O., Hauser, J. R., Simester, D. I., 2004. Polyhedral methods for adaptive choice-based conjoint analysis. J. Marketing Res. 41 (1), 116-131.

Train, K. E., 2009 Discrete Choice Methods with Simulation, Cambridge, UK: Cambridge University Press.

Troiano, S., Marangon, F., Tempesta, T., Vecchiato, D., 2016. Organic vs local claims: Substitutes or complements for wine consumers? A marketing analysis with a discrete choice experiment. New Medit 15 (2), $14-22$.

Williamson, P. O., Lockshin, L., Francis, I. L., Loose, S. M. 2016. Influencing consumer choice: short and medium term effect of country of origin information on wine choice. Food Qual Prefer 51, 89-99.

Williamson, P. O., Loose, S. M., Lockshin, L., Francis, L., 2017. Predicting wine repurchase: A case of low test- 
retest reliability in China. Int. J. Market Res. 59 (4), 471-494.

$\mathrm{Wu}, \mathrm{X} ., \mathrm{Hu}, \mathrm{B} ., \mathrm{Xiong}, \mathrm{J} ., 2019$. Understanding heterogeneous consumer preferences in Chinese milk markets: a Latent Class Approach. J. Agrc. Econ. doi:10.1111/1477-9552.12327

$\mathrm{Xu}, \mathrm{P} ., \mathrm{Zeng}, \mathrm{Y}$. C., 2014. Factors that affect willingness to pay for red wines in China. J. of Inter. Cons. Market. 26(5), 426-439.

Yu, J., Goos, P., Vandebroek, M., 2011. Individually adapted sequential Bayesian conjoint-choice designs in the presence of consumer heterogeneity. Int. J. Res. Market. 28 (4), 378-388.

Zhllima, E., Chan-Halbrendt, C., Zhang, Q., Imami, D., Long, R., Leonetti, L. Canavari, M., 2012. Latent class analysis of consumer preferences for wine in Tirana, Albania. J. Int. Food Agribus Market.24 (4), 321-338. 